\title{
A Study on Creating Awareness of Adverse Drug Reactions in Community Pharmacists in Bangalore
}

\author{
Kiran Nagaraju, Vanaja K Satheesh", Uday Shankar and Reshma Banu \\ Department of Pharmacy Practice, Visveswarapura Institute of Pharmaceutical Sciences, $24^{\text {th }}$ Cross, $25^{\text {th }}$ Main, BDA complex, BSK \\ $2^{\text {nd }}$ stage, Bangalore, India.
}

\begin{abstract}
Background: Drug related effects may lead to hospitalization, patient suffering and economic burden. Adverse Drug Reaction (ADR) monitoring and reporting system helps in detection and prevention of reoccurrence of some common and also rarest adverse drug reactions. The objective of this study was to create awareness among the selected community pharmacists and to improve their level of understanding about monitoring and reporting of adverse drug reactions to the pharmacovigilance centre around the facility. Method: The resent prospective study was conducted in hundred community pharmacists (chain \& private pharmacies) for a period of nine months in and around Bangalore city. The aim of our study was to create awareness in select community pharmacists about the adverse drug reactions by presenting visual presentation, displaying awareness posters at each pharmacies and distribution of yellow cards. Results: All the 100 respondents showed $100 \%$ response about the knowledge of ADRs, where to obtain the ADR forms and reporting of ADRs. 99\% of the respondents became aware of reporting ADRs. 96\% of respondents were aware that reporting of ADRs is an integral part of pharmaceutical care. Voluntary reporting of ADRs is agreed by $90 \%$ of the respondents. Only $8 \%$ of the respondents had received reports of ADRs from the patients and only $1 \%$ of respondents had reported an ADR. Hence, educating and training the pharmacists about the program was an important element which will improve and motivate community pharmacists to participate in reporting ADRs. Conclusion: The study reveals that awareness showed a positive response in improving the knowledge about ADRs. Well trained pharmacists in the area of ADR detection, reporting and monitoring will prove to be an asset in providing better patient care. Several approaches like continuing medical education (CME), training programmes, seminars and conferences adopted by the regulatory authorities would stimulate and become mandatory to the community pharmacists to be an integral part of reporting in ADR.
\end{abstract}

Key words: Awareness poster, ADR, Creating awareness, Questionnaire on ADR, Visual presentation, Yellow cards.

\section{INTRODUCTION}

A drug is defined as any substance or mixture of substances manufactured, sold, or represented for use in: the diagnosis, treatment, or mitigation, or prevention of a disease, disorder, abnormal physical state, or the physical symptoms thereof, in man or animal; restoring, correcting, or modifying organic functions in man or animal; or disinfection in premises in which food is manufactured, prepared, or kept. ${ }^{1}$

The World Health Organization defines an adverse drug reaction as "any response to a drug which is noxious and unintended, and which occurs at doses normally used in man for prophylaxis, diagnosis or therapy of disease, or for the modification of physiological function". ${ }^{2}$ Spontaneous adverse drug reaction (ADR) reporting is the cornerstone of pharmacovigilance. Pharmacovigilance is defined as "the science and activities relating to the detection, assessment, understanding and prevention of adverse effects or any other possible drugrelated problem". ${ }^{2}$ However, underreporting is a huge problem due to lack of reporting culture amongst healthcare professionals. ${ }^{3}$

In most countries, the spontaneous ADR reporting program mainly targets physicians
Submitted date : 02-03-2015 Accepted date : 28-03-2015

DOI: 10.5530/ijopp.8.2.5

Address for correspondence: Dr. Vanaja K Satheesh, Visveswarapura Institute of Pharmaceutical Sciences BSKII stage, BDA complex, Bangalore-560070, India.

E-mail:vanaja.sateesh@gmail. com

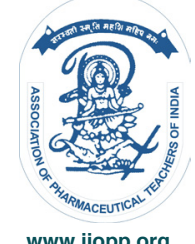

www.ijopp.org 
as the major source for reporting. However, in an attempt to increase reporting many countries allowed hospital pharmacists, community pharmacists, nurses and even patients to report ADRs. ${ }^{4}$ The World Health Organization (WHO) played an important role in establishing adverse drug reaction (ADR) monitoring programs in a few countries initially and later more countries started their own ADR monitoring programs. ${ }^{5}$

Adverse drug reactions (ADRs) contribute to the incidence of adverse events, resulting in increased healthcare costs. Therefore, it is important to motivate healthcare providers to understand their role and responsibility in the detection, management, documentation, and reporting of ADRs, all essential activities for optimizing patient safety. ${ }^{6}$

\section{Role of pharmacist's in preventing Adverse Drug Reactions}

Ensuring that medicines are used safely is fundamental in pharmaceutical care. Pharmacist's involvement in patient care should assist in prevention and early detection of ADRs. Studies have shown that pharmacist involvement has averted a large number of potential adverse reactions. Based on the knowledge of relevant patient and medication factors, pharmacists can ensure that prescribing is as safe and reasonableas possible. Pharmacists are also uniquely placed to identify ADRs occurring as a consequence of drug interactions. ${ }^{7}$

\section{Reporting of ADRs}

In India, the concept of clinical pharmacy is still in evolutionary stage and profession of pharmacists are underutilized health care professional. ${ }^{8}$ ADR monitoring was started in 1982 under the Chairmanship of Drug Control General of India (DCGI) and the programme is coordinated by the Department of Pharmacology at AIIMS as a National Coordinating Centre (NCC). ${ }^{9}$ The ultimate aim of pharmacovigilance is to ensure safe and rational use of medicines once they are released for general use in society. ${ }^{10}$ In India studies pertaining to ADR reporting in community set up are very low. Due to poor knowledge about the professional obligations, community pharmacists are confined to trade. Adequate motivation of community pharmacists will strengthen the reporting system. Thus, there is a need of designing and implementing the $\mathrm{ADR}$ reporting system in community pharmacists.

The current study on ADR program in Bangalore City was targeted to private and chain pharmacists to document and report ADRs. In order to investigate the reasons for the impact on the program development, a study was conducted to assess the attitude and knowledge of private and chain community pharmacists towards ADR reporting.
The objectives of the present study were to create awareness among select community pharmacists about ADRs, prepare posters for community pharmacy \& collect the ADR reported from community pharmacist.

\section{METHODOLOGY}

This was a prospective survey study, conducted for a period of nine months in 100 select approved community pharmacies in Bangalore city to create the awareness of adverse drug reactions. Amongst them two chain pharmacies were selected (Apollo and Sagar pharmacies in different areas of Bangalore city) and remaining all were individual owned community pharmacies. An informed consent was obtained from the chief pharmacist to educate them about the adverse drug reactions prior to the study. The complete project was carried out according to Declaration of Helsinki and approved by the Institutional Ethics committee of V.I.P.S, Bangalore

A self-designed questionnaire was prepared and validated, which included all the relevant data such as name, age, gender, education, pharmacist experience, duration of work, patient contact time, continuing education hours per month and relevant reference available in the pharmacy. The questionnaire also included the data which is useful in assessing the pharmacist knowledge such as the knowledge about the ADR, how to report ADRs, where to obtain ADR forms, and also the questionnaire to evaluate the pharmacist attitude towards ADR reporting.

Yellow cards were prepared and distributed which included name of the patient, age, sex, height, weight, date of the event occurring, brief description of the reaction, name of the suspected drug causing the ADR reaction, reaction stopping date, and name of the clinician reporting the ADR.

Visual presentation on adverse drug reactions was used to create the awareness of about ADRs in pharmacies which included; WHO definition of the ADR, how to report the ADRs, risks factors of ADRs and how to assess the causality of the ADRs and also the role of pharmacists in preventing and reporting of ADRs. ADR awareness posters were prepared and displayed in the prominent areas of community pharmacies where most of the customers could visualize. Yellow cards were distributed to pharmacists and informed them to report the suspected ADRs.

Following the awareness presentation and the prequestionnaire about ADR, a follow-up visit was done after a week to evaluate the level of understanding about the ADRs. The data collected was documented and assessed. 


\section{RESULTS \& DISCUSSION}

The present prospective study was conducted among hundred community pharmacists (from chain and private pharmacies) for a period of nine months in and around Bangalore city with the aim to create awareness for community pharmacist about ADR.

\section{Demographic details of the participants}

\section{Gender wise distribution}

Among 100 community pharmacists enrolled, 96 were male and four were female respondents. Our study resembles a survey, which was conducted by Saleh A Bawazir in Saudi Arabia there survey shows that male were more when compare to the female. ${ }^{4}$

\section{Age wise distribution}

Majority (56\%) of the participants were found to be in between the age group of 28 to 37 years followed by age of 18 to 27 years $(27 \%)$ followed by age group of 38 to 47 years (14\%). Three participants were more than 48years of age (Table 1).

\section{Education level of the pharmacist}

Table 1 also shows the educational level distribution of participants. 80 participants had completed diploma in pharmacy and 20 participants had completed bachelor of pharmacy and none of the pharmacist had post-graduate qualification.

\section{Work experience of the pharmacist}

Table 1 shows the work experience of the pharmacist. A total of 47 participants had an experience of 1 to 5years, 37 participants between 6 to 10years and 16 had more than 10 years.

\section{Pharmacist-Patient contact time}

Table 1 shows the patient contact time during the study. $26 \%$ of respondents estimated that they spent $<10 \%$ of their working time with patients, where as $8 \%$ of respondents indicated that they spent $>50 \%$ of their time, but majority of the respondents $(60 \%)$ could not specify due to many reasons like, lack of time, lack of knowledge, work pressure.

\section{Educational services rendered by the pharmacist in the study}

In order to obtain information as to how much of the working time was dedicated in providing education to the patients regarding drugs, usage, frequency, storage, re-filling, etc., data concerning time spent by the
Table 1: Demographics of the participating commu-

nity pharmacists

\begin{tabular}{|c|c|}
\hline Demographics & Percentage \\
\hline \multicolumn{2}{|l|}{ Age (in years) } \\
\hline \multicolumn{2}{|l|}{ Male } \\
\hline $18-27$ & 23 \\
\hline $28-37$ & 56 \\
\hline $38-47$ & 14 \\
\hline$>48$ & 3 \\
\hline \multicolumn{2}{|l|}{ Female } \\
\hline $18-27$ & 2 \\
\hline $28-37$ & 2 \\
\hline $38-47$ & 0 \\
\hline$>48$ & 0 \\
\hline \multicolumn{2}{|l|}{ Education } \\
\hline Diploma in Pharmacy & 80 \\
\hline Bachelor in Pharmacy & 20 \\
\hline \multicolumn{2}{|c|}{ Pharmacist experience in years } \\
\hline $1-5$ years & 47 \\
\hline $6-10$ years & 37 \\
\hline$>10$ years & 16 \\
\hline \multicolumn{2}{|c|}{ Pharmacist-Patient contact time } \\
\hline$>10 \%$ & 26 \\
\hline $10-50 \%$ & 6 \\
\hline$>50 \%$ & 8 \\
\hline Cannot specify & 60 \\
\hline \multicolumn{2}{|c|}{ Educational services rendered to the pharmacist } \\
\hline None & 42 \\
\hline $1-5$ hours & 4 \\
\hline $6-10$ hours & 49 \\
\hline$>10$ hours & 5 \\
\hline \multicolumn{2}{|l|}{ References available } \\
\hline CIMS & 76 \\
\hline MIMS & 1 \\
\hline CIMS + IDR & 10 \\
\hline CIMS + Drug update & 6 \\
\hline CIMS + Others & 7 \\
\hline
\end{tabular}

pharmacists in hours per month. It was observed that $49 \%$ of the respondents spent $6-10 \mathrm{hrs} /$ month educating the patients, where as $42 \%$ of the respondents did not render any educational services to the patients with $5 \%$ of the respondents spending time $>10 \mathrm{hrs} /$ month and $4 \%$ of the respondents spending $1-5 \mathrm{hrs} /$ month. This is depicted in the Table 1.

\section{References available at the community pharmacy}

It was observed that all the community pharmacists' used references such as CIMS, MIMS, CIMS+IDR, CIMS+Drug update and others (internet, contacts, agencies, etc.) in their day to day practice. Among which 
Table 2: Assessment of Pharmacists knowledge using Pre-Questionnaire and Post-Questionnaire

\begin{tabular}{|c|c|c|}
\hline Questions & Pre-Questionnaire & Post-Questionnaire \\
\hline \multicolumn{3}{|l|}{ Have you heard about ADR? } \\
\hline Yes & 91 & 100 \\
\hline No & 9 & 0 \\
\hline \multicolumn{3}{|c|}{ Do you know that ADR's can be reported? } \\
\hline Yes & 69 & 100 \\
\hline No & 31 & 0 \\
\hline \multicolumn{3}{|c|}{ Do you know where to obtain the ADR forms? } \\
\hline Yes & 1 & 100 \\
\hline No & 99 & 0 \\
\hline \multicolumn{3}{|c|}{ Have you ever reported any ADR? } \\
\hline Yes & 1 & 1 \\
\hline No & 99 & 99 \\
\hline \multicolumn{3}{|c|}{ Have you observed any ADR that caused? } \\
\hline Hospitalization & 85 & 85 \\
\hline A life threatening situation & 0 & 0 \\
\hline A congenital anomaly & 1 & 1 \\
\hline Death of a patient & 4 & 4 \\
\hline \multicolumn{3}{|c|}{ Have you received ADR reports from the patient? } \\
\hline Yes & 8 & 8 \\
\hline No & 92 & 92 \\
\hline If yes, how many ADR reports & 8 & \\
\hline \multicolumn{3}{|c|}{ Is reporting of ADR is a part of pharmaceutical care? } \\
\hline Yes & 78 & 96 \\
\hline No & 22 & 4 \\
\hline \multicolumn{3}{|c|}{ Before reporting any ADR, consulting doctor is important? } \\
\hline Yes & 90 & 100 \\
\hline No & 10 & 0 \\
\hline \multicolumn{3}{|c|}{ Do you think ADR reporting should compulsory? } \\
\hline Yes & 53 & 99 \\
\hline No & 47 & 1 \\
\hline \multicolumn{3}{|c|}{ Whether ADR reporting should be voluntary? } \\
\hline Yes & 16 & 90 \\
\hline No & 84 & 10 \\
\hline
\end{tabular}

majority used CIMS $(76 \%)$ as their first line references, whereas $10 \%$ used CIMS+IDR, $6 \%$ CIMS+Drug update, $7 \%$ CIMS+others and only $1 \%$ used MIMS has their primary reference (Table 1). It was observed that CIMS was the most common reference used by community pharmacists.

\section{Pre-Questionnaire to assess the knowledge of ADR}

In the present study, a pre-validated questionnaire was administered to survey the community pharmacists during which maximum number of the participants answered the questions which is depicted in Table 2. A pre-questionnaire was administrated to the 100 pharmacists, and when they were asked whether they were aware about ADR, 91 respondents had heard about ADRs whereas nine respondents had not heard. A similar study by Logas, Nigeria population lack of awareness of ADR reporting system in Nigerian population which was reflected by $63 \%$ of the respondents who did not know about the existence of a Yellow Card reporting scheme. ${ }^{11}$

When questioned whether they are aware that ADRs should be reported, 69 respondents were not aware about the reporting of ADRs. Among the 100 respondents only one respondent was aware about the ADR reporting forms, remaining 99 respondents were not aware about it and they were also not aware about where to get the forms. Previous surveys also mentioned education and training as important motivation factors. Reporting through the 
online internet may facilitate reporting according to some respondents and also the internet is an important logistic, that should be utilized to the maximum by the program. All aspects of the ADR reporting program should be placed in the internet and health care professional should be informed and encouraged to use it. ${ }^{4}$

When the respondent asked whether they have reported any ADR, only one respondent had reported an ADR and remaining 99 respondents were not aware about reporting of ADR. Most of the respondents were aware that reporting of ADRs is not a pharmaceutical care, like in most countries around the world. Ignorance and lack of time to fill in a report and a single unreported case may not affect ADR database. ${ }^{11}$ Eight respondents had received ADR reports from the patients; where as 92 respondents did not receive any ADR reports from the patients. As the respondents were not aware as to where the ADR should be reported, patients were referred back to the respective doctor. Similar finding of the study indicates that a very low participation (4\%) in reporting ADR and pharmacist claims cannot be verified. This finding is consistent with the low percent of pharmacists who were aware of the ADR reporting program in Saudi Arabia, revealed major barriers such as unavailability of the reporting forms, reporting forms is too complicated, and do not know how to report. ${ }^{4}$

78 respondents were aware that ADR reporting is a part of pharmaceutical care whereas 22 respondents were not aware that reporting of ADRs is a part of pharmaceutical care. This shows that majority of the respondents knew that reporting of ADRs accounts a part of pharmaceutical care. A study by Ghosh S, et al, shows that there was a positive attitude of community pharmacist towards ADR reporting, because of the vast majority of respondents $(90 \%)$ reporting of suspected ADR is a part of professional obligation and $97 \%$ of respondents considered ADR reporting is an integral part of pharmaceutical care. ${ }^{4}$ Ghosh S, et al., revealed that majority $(95 \%)$ of respondents not only reported that ADR reporting and monitoring system is beneficial to the patients, but also pharmacist involvement in the detection, reporting, monitoring and management of ADRs is very useful. ${ }^{12}$

Majority of the respondents $(90 \%)$ thought that consulting doctor before reporting any ADR was important; whereas 10 respondents thought that consulting the doctor was not an important step to report ADR. Out of 100 pharmacist, 53 pharmacists answered that ADR reporting should be compulsory whereas 47 pharmacists answered that ADR reporting was not compulsory. Similar findings were reported by previous surveys, consultation with physician regarding reporting ADR by community pharmacists should not be part of the program, since this may become a barrier for reporting and make the pharmacists dependent on physician opinion. 784 respondents denied for voluntary reporting of $\mathrm{ADR}$ and the rest 16 respondents were proactive in reporting of ADR to the concern authority.

A visual power point presentation consisting of $\mathrm{ADR}$ definition, effect of ADR on health care, examples of $\mathrm{ADR}$, types of $\mathrm{ADR}$, risk factors of $\mathrm{ADR}$, detection of $\mathrm{ADR}$, diagnosis of $\mathrm{ADR}$, prevention of ADR, reporting of ADR, reasons of ADR, management of ADR and significance of reporting ADR was presented to individual pharmacist after they answered the pre-questionnaire with the intention to create awareness and improve their level of understanding about monitoring and reporting of ADR. ADR awareness poster was prepared and posted in each of the community pharmacies along with the printed ADR reporting form.

\section{Post-Questionnaire to assess the knowledge of ADR}

After creating awareness with visual presentation a post-questionnaire was administered with the follow up of a week period with the same questions that of the pre-questionnaire, which is shown in Table 2. In the follow-up visit when the pharmacist was asked whether they have heard about ADRs, $100 \%$ of the respondents agreed to have knowledge about ADRs of which only nine $\%$ of the community pharmacists agreed in prequestionnaire session. In the post-questionnaire survey $100 \%$ of respondents were aware that ADRs should be reported and this can help in the pharmaceutical care (in comparison to $31 \%$ who did not respond in prequestionnaire). All the pharmacists were now aware about the ADR monitoring forms, where to obtain and where to report (in comparison to $99 \%$ in pre-questionnaire).

When the pharmacists were asked whether they had reported any ADR in the past or post educational session, 99\% had not reported ADRs. Pharmacists had not received any ADR reports within the one week gap of pre and postquestionnaire administration. Visual presentation on ADR had a significant effect regarding reporting of ADR and considered to be a part of part of pharmaceutical care. In the follow-up visit, majority of the respondents (96\%) accepted that $\mathrm{ADR}$ reporting is a part of pharmaceutical care.

After post-educational session, $100 \%$ of respondents agreed that before reporting any ADR consulting the doctor was important, which can increase the interpersonal rapport between the doctor, pharmacist and patients. Majority of the respondents (99\%) agreed

Indian Journal of Pharmacy Practice, Vol 8, Issue 2, Apr-Jun, 2015 
ADR reporting should be compulsory and $90 \%$ of the respondents believed that ADR reporting should be voluntary with only $10 \%$ of the respondents not agreeing for reporting of ADR.

\section{CONCLUSION}

This study reveals that creating awareness about ADRs among the community pharmacists, made a very huge impact on level of understanding, attitude towards reporting of ADRs. Detection and prevention of ADRs at the earliest can not only reducemorbidity and mortality but also bring down the cost of their management which can otherwise burden the economic status of the

\section{REFERENCES}

1. Work place safety and health division, drug (http://www.gov.mb.ca/labour/ safety/whmisglossary.html).

2. Faria Z. Pharmaceutical Information for you [Articles on the internet] 2009 [cited2010 Nov 1]. Available from: Pharmainfo.net/Zarrinfaria/adversedrugreaction-monitoring.

3. Pankaj Gupta, Aaditya Udupa. Adverse drug Reaction Reporting and Pharmacovigalance: Knowledge, attitude and Perception amongst Resident Doctor's. Pharm Sci Res. 2011; 3(2): 1064-9.

4. Bawazir AS. Attitude of community pharmacists in Saudi Arabia towards AD Rreporting. Saudi Pharma J. 2006 Jan; 1(14): 75-83.

5. Subish P, Izham M, Pranya M, Arjun P. Knowledge, attitude and practices of thecommunity pharmacists in Nepal towards ADRs and Pharmacovigilance. Indian J Pharm Pract. 2009 Oct; 2(4): 29-37.

6. Zolezzi M, Parsotam N. Adverse Drug Reaction reporting in Newzealand: implications for Pharmacists. Therapeutics and Clin Risks Management 2005; 1(3): 181-8

7. Parthasarathy G, Karin Nyfort-hansen, Milap N. Clinic Pharmacy Book: Essential Concepts and Skills. Hyderabad: Universities Press; 2008. 43-53. developing countries like India. Well-trained pharmacists in the area of ADR detection, reporting and monitoring will prove to be an asset in providing better patient care. Several approaches like continuing medical education (CME), training programmes, seminars and conferences should be adopted by the regulatory authorities to stimulate the community pharmacists to be an integral part in reporting of ADRs.

\section{ACKNOWLEDGEMENT}

We would like to thank the Principal, Dr.D.H.Harish Kumar, and the Management of the Chain Pharmacies for supporting our work.

8. Ramesh M, Pandit J, Parthasarathi G. Adverse Drug Reaction in a South Indian hospital- their severity and cost involved. Pharmacoepidemiology and Drug safety Inter science 2003; 12(8): 687-92. (www.interscience.wiley.com), DOI: 10.1002/pds.871).

9. Community pharmacovigilance in Nepal, a publication of regional pharmacovigilance centre western Nepal. Manipal teaching hospital, Pokhara, Nepal.

10. Leon Shargel, Alan H, Mutnick, Paul F, Souney Larry N, et al. Adverse Drug Reaction Reporting, Fourth Edition, Comprehensive Pharmacy Review Lippincott Williams and Wilkins, Printed in India at Gopsons papers Itd, Noida Re-printed; 2001, 416-21.

11. Parthasarathy G, Karin Nyfort-hansen, Milap N. Clinic Pharmacy Book: Essential Concepts and Skills. Hyderabad: Universities Press; 2008. Pg. 4353.

12. Ramesh M, Parthasarathi G. Adverse drug reactions reporting: attitudes and perceptions of medical practitioners. Asian J Pharm and Clin Res. 2009 AprilJune; 2(2): 10-4. 